\title{
A MÍIIA, AS CRIANÇAS E A PRODUÇÃO DE CONTEÚDO CULTURAL
}

\section{THE MEDIA, CHILDREN AND THE CULTURAL CONTENT PRODUCTION}

\section{LIGIA STELLA BAPTISTA CORREIA ${ }^{1}$.}

Resumo: Nos últimos anos tem se acirrado a crítica a respeito do excesso de estímulos publicitários e conteúdos midiáticos de baixa qualidade destinados as crianças. Os foros de discussões são crescentes a respeito do consumismo exacerbado e as longas horas de exposição à televisão e todo o entretenimento de tela como computadores, tablets, celulares e vídeo games. Porém, considerando a dinâmica familiar e os espaços que são destinados a expressão das crianças está cada vez mais escassa. Pouco tem sido feito no sentido de dar voz às crianças para que elas possam oficialmente participar da construção da cultura que a cerca. A midia é o caminho mais fácil e pode contribuir muito para a formação de cidadãos mais ativos, isso pode ser comprovado com o caso da Revista Recreio da década de 1970, crianças podem e querem fazer parte da cultura e contribuir com conteúdo, o que falta é o convite.

Palavras-chave: crianças; mídia; consumo; conteúdo; cultural.

Abstract: In the last years the growth of criticism involving the excess of advertising stimulus and low quality mediatic content destined to children has increased quite visibly. The forums of discussions about the excess of consumerism, the long hours in front of TV and all the gadgets such as computers, tablets, cell phones and videogames, are increasing. However, considering the family dynamics and the areas that are destined to the kids expressions are even rarer. Little have been done to address kids’

\footnotetext{
1 Mestre em Ciências Sociais pela PUC-SP. Bacharel em comunicação social com habilitação em propaganda e marketing pela Universidade Presbiteriana Mackenzie (2000), especialização em Marketing pela Fundação Getúlio Vargas (2002). Mais de 10 anos de experiência no mercado de bens de consumo atuando na área de marketing com foco em consumo e conhecimento do consumidor, maior experiência com público infantil. Atualmente é professora do programa de pós-graduação da FMU na área de Comunicação e Marketing. Ligias.correia@gmail.com
} 


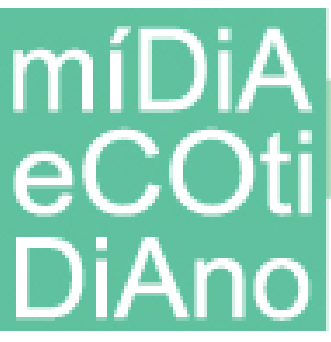

freedom of speech in order that they are officially engaged with the culture that surrounds them. The media is the easiest way and should contribute a lot to the formation of more active citizens. This can be verified with Recreio Magazine case study (1970's). Kids can and want to be part of the culture and produce content, what's missing is an invitation.

Key words: children; media; consumption, content, cultural.

\begin{abstract}
A aprendizagem da vida iria ser feita segundo duas vias, a vida interior e a vida exterior. A vida interior passa pelo exame de si, a auto-análise, a autocritica. O auto-exame deve ser ensinado desde o ensino primário e ao longo deste. Ensinar-se-ia sobretudo os erros ou deformações que sobrevêm nos testemunhos mais sinceros ou convencidos; estudar-se-ia a forma em que o espírito oculta os factos que incomodam a sua visão das coisas: mostrar-seia como esta visão das coisas dependem menos das informações que da forma como é estruturado o modo de pensar. A vida exterior seria a introdução ao conhecimento dos media . Como as crianças são muito cedo imergidas na cultura mediática, televisão, jogos de vídeo, anúncios publicitários, etc., o papel do mestre não é o de denunciar, mas fazer conhecer os modos de produção desta cultura (MORIN, 2002, p. 83-84).
\end{abstract}

Ao acessar o Youtube é possível reparar que, entre os vídeos mais vistos, sempre há um cujo protagonista é uma criança, material recolhido por pais orgulhosos que gostam de mostrar todo potencial de seus filhos ao mundo. O facebook e as demais redes sociais também são cenários de comportamentos desse tipo: usuários geram conteúdos e compartilham a beleza e a sagacidade de seus filhos em fotos, vídeos e depoimentos; as crianças acabam estrelando produtos culturais da atualidade. Alguns desses produtos tornam-se fenômenos de audiência, e isso faz com que eles passem a serem considerados conteúdos relevantes para a mídia convencional também, como o caso dos irmãos ingleses ${ }^{2}$ Harry e Charlie, cujo filme ultrapassa 460 milhões de visualizações, recorde do Youtube. Independente do formato - vídeo, foto ou depoimentos - as crianças são elementos importantes para o sucesso e repercussão do material divulgado; se não participam como protagonistas estão em grande parte das produções. O curioso é que raramente há disponível para visualização um produto elaborado pelas crianças.

\footnotetext{
${ }^{2}$ Vídeo Charlie bit me: http://www.youtube.com/HDCYT\#p/u/0/_OBlgSz8sSM
} 


\section{míDiA

Ao mesmo tempo em que esses conteúdos desenvolvidos pelas famílias lideram os vídeos mais vistos, diariamente novos países entram na discussão sobre a proibição da publicidade infantil e a regulamentação da programação televisiva por faixa etária, como tem acontecido no Brasil desde $2001^{3}$. Paradoxo que comprova a urgência de trabalhar o fato que Henry Jenkins (2009) aponta como fundamental nos tempos de tecnologias digitais: a educação para a mídia.

O objetivo deste artigo é iniciar uma discussão sobre o papel do consumo de produtos culturais no incentivo à postura participativa do consumidor infantil e sobre a possibilidade de encorajar a sua participação na construção de conteúdos que irão impactar o coletivo. A ideia surgiu ao mapear o espaço destinado às crianças na mídia e ao conhecer o convite feito para que contribuíssem para o conteúdo da revista Recreio, da Editora Abril. O comparativo entre produtos culturais dessa indústria em momentos diferentes retrata como os produtos culturais podem estimular a atuação das crianças como produtoras de conteúdo e, portanto, como cidadãs mais atuantes. A metodologia utilizada nessa pesquisa foi uma etnografia de produto feita a partir da leitura e análise de 985 edições da Revista Recreio, sendo 453 exemplares da primeira versão da revista cuja circulação foi entre 1969 e 1982; e 532 edições da versão atual da revista lançada em 2000 e ainda em circulação. O campo aconteceu entre 22/03/2010 e 20/05/2010 nas instalações da editora Abril em São Paulo ${ }^{4}$.

As crianças estão mais frequentes na pauta de discussão das mídias desde a Convenção Internacional sobre os Direitos das Crianças ${ }^{5}$, adotada pela Assembleia Geral das Nações Unidas, de 1989. A partir disso, mais canais de TV foram criados para audiência, que, segundo David Buckingham (2007), é bastante crítica e faz suas escolhas. Paralelamente, no extremo oposto, há uma batalha para a preservação da infância inocente, uma luta para que a ideologia consumista fique longe desses seres

\footnotetext{
3 Projeto de Lei 5921/01: proíbe a publicidade dirigida às crianças e regulamenta a dirigida a adolescentes.

${ }^{4}$ Mais detalhes sobre a pesquisa de campo ver CORREIA, 2010 disponivel para acesso em: http://www.sapientia.pucsp.br/tde_busca/arquivo.php?codArquivo=12249.

${ }^{5}$ Disponível em: http://www.unicef.org/brazil/pt/resources_10120.htm
} 


\section{míDiA

ingênuos, em desenvolvimento, que não podem ser expostos a tantos estímulos maus, capazes de gerar atitudes inconsequentes desde cedo ${ }^{6}$. Buckingham (2007) compara as linhas muito otimistas e muito pessimistas sobre a relação das crianças com as mídias e propõe um meio termo para desenvolver os novos estudos. Aponta também os riscos de restringir o contato das crianças com o mundo e com o mercado, tal como pregam os discursos mais radicais.

Apesar de toda essa preocupação com os conteúdos destinados às crianças, o movimento no sentido de considerá-las produtoras de cultura é pouco significativo. Ainda que as crianças sejam incluidas como objeto e mesmo sujeito em alguns estudos relacionados à mídia, nem sempre suas vozes reverberam além dos limites da academia. Uma movimentação, desde os anos 2000, tem ganhado proporção mundial: é a constituição do campo da sociologia da infância, cujo principal ganho é o estabelecimento da criança como um ator social completo (SARMENTO, 2005) em contraponto à menoridade total, como são classificadas. Essa perspectiva contribui para o incentivo à atuação das crianças como produtoras de conteúdo para a mídia e, consequentemente, para o desenvolvimento de uma prática mais participativa impactando diretamente a formação cidadã.

Hoje as crianças são um público muito almejado pela indústria em geral, sobretudo a de bens culturais. As crianças desde cedo são introduzidas no papel de consumidoras e estimuladas pela família a fazerem suas escolhas (MC NEAL, 1998). A indústria, por sua vez, patrocina pesquisas para acompanhar a preferência desse público bastante exigente (BUCKINGHAM, 2007). Na esfera do mercado as pessoas podem exercer suas escolhas e estampá-las em seus hábitos através das mercadorias que consomem. O espaço político está cada vez mais restrito, ou menos atrativo, aos cidadãos, que têm suas escolhas cada vez mais favorecidas no ambiente do mercado (CANCLINI, 2006). Nesse contexto, a esfera do consumo atrai mais as crianças que os

\footnotetext{
${ }^{6}$ Esse é o tipo de argumentação defendida pelo Instituto Alana e seguidores, para mais detalhes sobre a proposta da organização visite o site: http://www.alana.org.br/CriancaConsumo/ConsumismoInfantil.aspx
} 


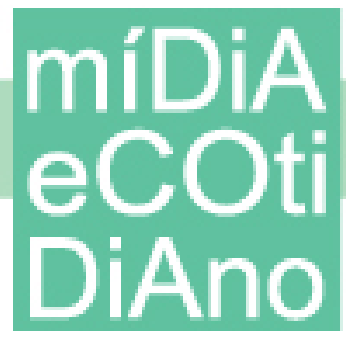

adultos, pois, como a atuação político-social se torna mais distante, a do mercado é favorecida.

A relação entre consumo infantil e formação de futuros cidadãos soa de início, como uma questão intrigante e, por isso, deve ser estudada. Se a perspectiva do consumo, enquanto inspiração para a prática da cidadania pode ser muito produtiva quando aplicada a adultos, certamente será ainda mais se praticada desde a infância. O aprendizado de uma atuação mais participativa nesse campo do consumo pode ser uma maneira de gerar experiência e conhecimento para uma postura semelhante no campo social e político e, quanto mais cedo acontecer, mais habitual será, como ensina a sociologia do gosto de Bourdieu (1999).

Surge, nesse debate, a possibilidade de um caminho para pensar a experiência do consumo como um treino para a atuação participativa (CANCLINI, 2006), inclusive pelo fato de se ensinar nas escolas como consumir e utilizar a tecnologia e as novas perspectivas da mídia. As teorias de inteligência coletiva e atuação colaborativa no consumo vêm fortalecer essa possibilidade. Henry Jenkins (2009) aponta que os indivíduos que fazem uso frequente dos meios digitais agrupam-se e atuam em comunidades nas quais compartilham suas experiências, o que faz com que eles fiquem mais fortes, com mais chances de promover mudanças; é a inteligência coletiva construída em conjunto.

As crianças, nesse cenário de consumo como identidade, têm muito a contribuir, pois são produtoras de cultura e conteúdo (BUCKINGHAM, 2007); mais do que criaturas que se apropriam de valores e coisas que são ensinadas ao longo dos dias, elas também elaboram sua visão para dar sentido ao mundo que as rodeia. A criança não sabe menos que os adultos; sabe outras coisas (COHN, 2005). Esse pressuposto aponta uma perspectiva produtiva no que diz respeito ao que pode ser estimulado, na infância, para mudar a relação das pessoas com a mídia e, portanto, com a sociedade, estimulando a atuação cidadã.

O exercício da cidadania entre os consumidores poderá ser mais rápido e eficaz se contar com a força da distribuição e o incentivo da mídia, logo, quanto antes os 


\section{míDiA \\ eCO \\ DiAno}

consumidores espectadores forem convocados a participar, maior a chance de bons resultados, pois os pequenos consumidores de hoje poderão aprender a serem cidadãos mais atuantes amanhã. “A cidadania já não se constitui apenas em relação a movimentos sociais locais, mas também em processos de comunicação de massa” (CANCLINI, 2006, p.110).

\section{Editora Abril e “as revistas” Recreio}

A Editora Abril iniciou suas operações no Brasil com o lançamento, em 12 de julho de 1950, de um título destinado ao público infantil, a revista em quadrinhos O Pato Donald. O título foi o primeiro de uma extensa linha de quadrinhos de sucesso, cuja receita subsidiou outros projetos dentro da editora. Mas não foi só com personagens Disney que se desenhou a história das publicações infantis na editora; em julho de 1969, foi lançada a Revista Recreio.

A “revista brinquedo" ficou em circulação entre julho de 1969 e maio de 1982. Nessa primeira fase, que durou 12 anos, foi um dos sucessos editoriais destinados ao público infantil e registrou alta tiragem, com histórias de grandes autores brasileiros, curiosidades folclóricas, científicas e de interesse geral, sempre acompanhada de um brinquedo, fosse no encarte para ser montado ou mesmo um brinde. Depois de duas décadas, a Abril lançou, em março de 2000, a nova Recreio com o objetivo entreter e informar as crianças com notícias, um brinquedo e uma coleção. Os dois projetos editoriais de Recreio propuseram-se a levar, de maneira divertida, informação de qualidade às crianças. Ambos buscaram adequação aos interesses de seu público enquanto estavam no mercado e, dessa forma, endereçar ${ }^{7}$ a revista e seu conteúdo ao leitor. É explícita a semelhança dos produtos quanto aos seus objetivos; ambos têm histórias, atividades e brinquedos interativos, fórmula de sucesso junto às crianças, comprovada pelas tiragens, que chegaram, em ambos os casos, a 250 mil exemplares por edição.

\footnotetext{
${ }^{7}$ Para mais detalhes sobre o conceito de endereçamento de produtos culturais, ver Ellsworth, 2001.
} 


\section{míDiA

Na análise comparativa dos produtos, com foco no estímulo à produção de conteúdo por parte da criança, é possível identificar pontos divergentes. A versão mais recente da revista Recreio usa temas da atualidade, principalmente ligados a produtos culturais como cinema, séries de televisão e videogames, para compor seu conteúdo. Um exemplo é a utilização do filme Como treinar o seu dragão para passar informações sobre os Vikings, na edição 523 de 2010. Mesmo com abordagens e temas interessantes, o destaque da capa e, portanto, a maior parte do conteúdo da edição sempre se destina ao produto cultural que está sendo lançado; nota-se a ausência de espaço para os leitores na construção dos conteúdos. A Recreio da década de 70 propôsse a estar próxima das crianças, levando informações que lhes interessavam e também trazendo-as para o universo da revista. Isso não acontece com a revista atual: embora os leitores sejam convidados a enviar perguntas e desenhos, não fica claro o espaço disponibilizado para a sua participação. A comparação entre as edições do $10^{\circ}$ aniversário das revistas deixa clara essa diferença.

Na Edição 390, de 1979, a capa destacava, para os 10 anos da revista, duas crianças lendo a edição número 1 . O conteúdo trazia a cobertura da festa realizada na redação e o texto convidava o leitor a se colocar na história da revista com perguntas como: “Você já tinha nascido quando Recreio nasceu?” Além disso, a equipe que fez a revista também fez parte da matéria, informando ao leitor a função de cada um, procurando desmistificar o trabalho desenvolvido, com o objetivo de despertar o interesse da criança pelo processo e mostrar-lhe os bastidores da revista. A Edição 523, de 2010, também foi comemorativa, mas isso não foi mencionado na capa; o conteúdo da edição apresentou uma matéria sobre aniversários e festa surpresa sem nenhum destaque para a história da revista ou sua relação com o leitor durante esse tempo.

A diferença de relacionamento da equipe editorial com os seus leitores é nítida. A Recreio atual traz, em toda edição, dois convites aos leitores para participarem do conteúdo da revista: na página final e na seção Curiosidades há um "Escreva para a gente!” seguido do telefone, e-mail, site e endereço de correio regular. Não há uma 


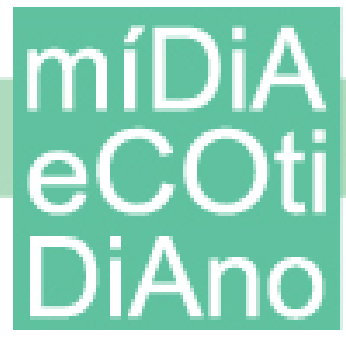

regra específica para participar, os leitores podem escrever o que quiserem. Já a Recreio da década de 1970 apresentava evidente predisposição para construir o seu conteúdo em conjunto com os leitores; ao longo dos 12 anos de existência houve diversas iniciativas que comprovam isso, desde o Correio dos amiguinhos de Recreio até as mesas redondas, pesquisas de opinião, jornaizinhos, concursos. Em alguns casos, as crianças mandavam suas histórias e entrevistas para a revista, as quais eram publicadas. Essa participação era estimulada em todas as edições com instruções objetivas a respeito do tipo de conteúdo que os leitores deveriam enviar e até sugestões de como eles poderiam buscar as informações ${ }^{8}$. Apesar da possibilidade de contato existir nas duas versões, a diferença entre a participação dos leitores em cada uma delas é expressiva; a versão antiga apresenta muito mais conteúdo dos leitores do que a atual, reflexo do espaço destinado às crianças.

\section{Considerações finais}

O mundo é comandado por adultos e até mesmo os produtos midiáticos para crianças são feitos por gente grande. Às vezes, quando a criança toma a iniciativa de participar, é hora de outra atividade qualquer e deixa-se para depois, um depois distante que, muitas vezes, não dá oportunidade para uma conversa no futuro (ARATANGY, 2009). Esse tipo de postura na construção da relação com as crianças desperdiça a oportunidade da criação de diálogos mais ricos e construtivos, sobretudo pelo ponto de vista dos conteúdos possíveis. As crianças têm uma autonomia cultural em relação aos adultos, pois interpretam o mundo de uma maneira diferente e são produtoras de cultura (TOREN, 1993). É fácil, porém, identificar como o mundo adulto não considera a possibilidade da produção midiática infantil ou a criança como sujeito protagonista da comunicação, pois não há espaço para esse diálogo ou participação em nenhum meio de comunicação.

8 Para referências e exemplos do convite das duas revistas, ver CORREIA, 2010. 


\section{míDiA

A maioria dos debates sobre crianças e mídia sugere o afastamento, a proibição de produtos voltados a esse público, alegando que prejudicam sua formação. Porém é possível estimular as crianças a se apropriarem de um espaço disponível no universo da mídia digital; basta incentivá-las. Nem mesmo o convite é preciso, pois, numa época em que a cultura participativa é realidade, os consumidores participam até mesmo sem serem convidados. Nesses meios, o público em geral tem uma postura mais ativa e produz conteúdo continuamente, o que não acontece com as crianças, que, desde cedo, aprendem em casa que seu local de participação é a escola.

Portanto não se deve esquecer que o engajamento virtual é um exercício de cidadania que pode impactar um grupo muito maior de pessoas. As crianças, menos resistentes às novas tecnologias, por princípio, deveriam ser os produtores mais ativos nesse cenário. Mas o mundo adultocêntrico continua dizendo que ainda não é para elas essa tarefa, reduzindo-as a figurantes dos produtos que são veiculados a cada minuto. Reduzindo o espaço de protagonismo das crianças às salas de aulas nas escolas, quando elas poderiam contribuir muito mais para a construção de conteúdo e também de uma atuação mais participativa da população. Assim sendo, a oportunidade de mudança no paradigma da educação para a midia está tanto na educação formal, no currículo escolar, quanto nas familias, pois além do conhecimento teórico, o corpotamental influencia muito mais as crianças do que o discurso (COLES, 1998), dessa forma os adultos não deveriam criticar seus filhos por assistir muita televisão quando eles mesmos o fazem , gerando conflitos na educação moral.

Uma das hipóteses para a baixa produção e participação das crianças nos meios de comunicação é que elas desconhecem de até onde podem ir, além da falta de incentivo. Mas, quando ultrapassam essas barreiras, fazem diferença com sua atuação participativa. É o caso de René Silva, fundador do portal Voz da Comunidade ${ }^{9}$. Aos 11 anos criou o jornal Voz da Comunidade, no complexo do Alemão, usando o aprendizado adquirido ao participar do jornal da escola. Ele mesmo produzia as matérias e

9 Ver mais informações no portal http://www.vozdascomunidades.com.br/ ou no Twitter @vozdacomunidade. 


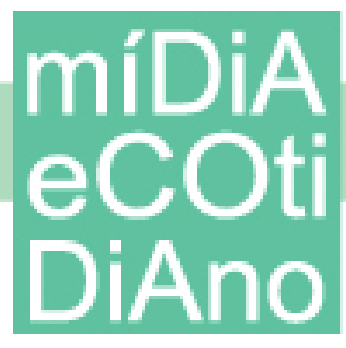

comercializava os espaços para publicidade. O jornal do René cresceu e transformou-se em um portal. A ideia surgiu durante a ocupação do complexo do Alemão, em 2010, quando, no Twitter, ele mandava notas atualizando os acontecimentos no morro, conteúdo utilizado pela imprensa na ocasião.

A atuação da educação para a mídia pode contribuir muito para a formação de cidadãos mais ativos e articulados. Como Morin (2002) coloca na frase que abre esse artigo, ao invés de proibir e afastar as crianças dos estimulos da midia, o ideal é que a vida exterior, a escola e a família em especial, estimule-as a conhecer os processos de produção para que construam uma visão critica a respeito das mensagens e como são impactadas por elas ao invés de serem isoladas. É um processo árduo esse da educação, mas estaria cumprindo o seu papel, uma vez que é a responsável pelo encoragamento da atuação cidadã. A midia pode ser protagonista nessa mudança de paradigma, impactando um número infinitamente maior de expectadores do que a educação formal.

Os meios de comunicação, ao estimularem a produção de conteúdo pelas crianças - como é o caso da Revista Recreio da década de 1970 - podem estabelecer essa prática desde cedo, além de agregar novos pontos de vista aos produtos que comercializam, ampliando a qualidade do que é transmitido ao público em geral. Para tanto, faz-se urgente o estabelecimento de uma agenda para a educação para a mídia dirigida às crianças e inclusive aos adultos que convivem com elas, para que as barreiras possam ser ultrapassadas e conteúdos sejam produzidos pelo público infantil. A troca de conteúdo entre crianças e adultos, já produtores, enriquecerá a programação dos meios convencionais e desenvolverá, nos futuros cidadãos, uma postura mais atuante.

O objetivo do presente artigo é iniciar uma discussão sobre o papel do consumo de produtos culturais no incentivo à postura participativa do consumidor infantil e sobre a possibilidade de encorajar a sua participação na construção de conteúdos, além dos pontos de vista teóricos levantados e comentados nesse desenvolvimento cabe também trazer alguns exemplos práticos de como estimular as crianças a produzir conteúdo e ter uma postura mais ativa diante da midia. Desde 


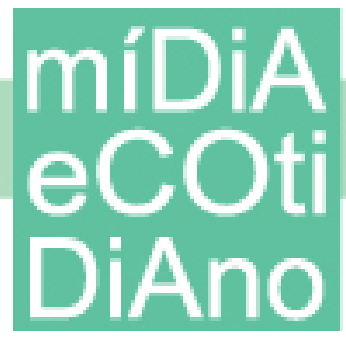

iniciativas despertadas em práticas na escola como o caso do René Silva e o Portal Voz da Comunidade apontam como a inclusão de práticas de educação para a midia nas escolas tem um papel fundamental em influenciar essa atitude. A midia, por sua vez, também pode contribuir consideravelmente, o exemplo da Revista Recreio da década de 1970 comprova essa importância ao estimular seus leitores a enviar conteudo produzido por eles para compor a revista e a participação mais ativa e constante comparada ao publico atual do mesmo título. Outra iniciativa bastante simples e de fácil implementação retoma a constatação de abertura deste artigo, os pais tem publicado quantidade significativa de conteúdo protagonizada por crianças, desde filmes, fotografias e descrições de situações e comentários. Entregar as ferramentas nas mãos delas para que preparem um conteudo, seja da familia ou de qualquer outro assunto, ou até mesmo convidá-los a produzir em conjunto é dar voz as crianças nos canais digitais. Indepentende de qual seja a iniciativa, é urgente começar de alguma forma, não se sabe ao certo qual o melhor caminho ou formato para essa prática, como Jenkins (2009) coloca ainda estamos aprendendo como atuar nessa nova realidade, a cultura colaborativa permite inclusive o compartilhamento das boas práticas para que sejam multiplicadas. A inteligência coletiva certamente poderá apontar qual o caminho ou formato mais efetivo para incluir na rotina dos cidadãos a educação para a midia e para o consumo, tanto para crianças quanto para seus pais, todos nós podemos começar a exercitá-la no proximo post.

\section{Referências Bibliográficas}

ADORNO, Theodor W. Educação e emancipação. Rio de Janeiro: Editora Paz e Terra, 1995.

ALONSO, Luis E. La era del consumo. Madrid: Siglo XXI Editores, 2006.

ANDI. Cidadania antes dos 7anos: a educação infantil e os meios de comunicação. São Paulo: Cortez, 2003.

ARATANGY, Lidia. O anel que tu me deste: o casamento no divã. São Paulo: Primavera Editorial, 2009. 


\section{míDiA \\ e DiAno}

ARIÈS, Philippe. História social da criança e da família. Rio de Janeiro: LTC Editora, 1978.

BORELLI, Silvia H. S. Ação, suspense, emoção. Literatura e cultura de massa no Brasil. São Paulo: EDUC: Estação Liberdade, 1996.

BOURDIEU, Pierre. La Distinción. Madrid: Taurus, 1999.

BRASIL. Estatuto da criança e do adolescente. Decreto- Lei No 8069, de 13 de julho de 1990. Brasília: coordenação de publicações, 1991.

BUCKINGHAM, David. Crescer na era das mídias eletrônicas. São Paulo: Edições Loyola, 2007.

CANCLINI, Nestor G. Consumidores e cidadãos: conflitos multiculturais da globalização. Rio de Janeiro: UFRJ, 2006.

COHN, Clarice. Antropologia da criança. Rio de Janeiro: Jorge Zahar, 2005.

COLES, Robert. A educação moral das crianças. Rio de Janeiro: Editora Campus, 1998

CORREIA, Ligia. O consumo serve para pensar: Revista Recreio, crianças e alternativas para a formação de cidadãos. Dissertação (Mestrado em Ciências Sociais) - PUC-SP. São Paulo, 2010.

CORSARO, William A. Sociologia da infância. Porto Alegre: Artmed, 2011.

ELLSWORTH, Elizabeth. "Modo de endereçamento: uma coisa de cinema; uma coisa de educação também.” In: SILVA, Tomaz T. (Org.). Nunca fomos humanos - nos rastros do sujeito. Belo Horizonte: Autêntica, 2001. pp. 7-76.

JENKINS, Henry. Cultura da convergência. São Paulo: Aleph, 2009.

MACHADO, Nilson J. Cidadania e educação. São Paulo: Escrituras editora, 1997.

MARTÍN-BARBERO, Jesús. Os exercícios do ver: hegemonia audiovisual e ficção televisiva. São Paulo: Editora SENAC, 2001.

MORIN, Edgar. Repensar a reforma. Reformar o Pensamento: a cabeça bem feita. Lisboa: Instituto Piaget, 2002.

PIAGET, Jean. A linguagem e o pensamento da criança. São Paulo: Martins Fontes, 1993.

SARMENTO, Manuel J. "As culturas da infância nas encruzilhadas da $2^{a}$ modernidade”. In: SARMENTO, M. J. e CERISARA, A B. (org). Crianças e Miúdos: Perspectivas Sociopedagógicas da Infância e Educação. Porto: Asa, 2004.

TOREN, Christina. Making history: the significance of childhood cognition for a comparative anthropology of mind. Man, New series, vol. 28, n. 3, pp 461-478, Sep, 1993. 